\title{
Burden of disease attributable to vitamin A deficiency in Iranian population aged less than five years: findings from the global burden of disease study 2010
}

Maryam Bahreynian ${ }^{1}$, Mostafa Qorbani ${ }^{2,3^{*}{ }^{+}}$, Shohreh Naderimagham ${ }^{3,4}$, Sara Nejatinamini ${ }^{3}$, Asal Ataie- Jafari ${ }^{5}$,

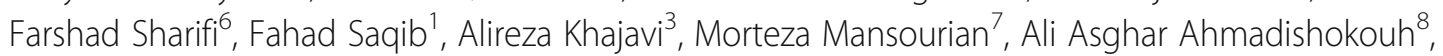

Hamid Asayesh ${ }^{9}$, Omid Safari ${ }^{2}$ and Roya Kelishadi ${ }^{*+}$

\begin{abstract}
Background: Vitamin A deficiency (VAD) is considered as one of the most serious public health concerns in developing countriesand the leading cause of mortality in under-five-year-old children.A large number of young children and pregnant women especially in low-income, non-industrialized communities are more susceptible to VAD. This study aims to report the burden of disease (BOD) attributable to VAD in Iranian population aged less than 5 years by using data of the Global Burden of Disease (GBD) study 2010.

Methods: The GBD 2010 study calculated the proportion of deaths, years of life lost (YLLs), and years lived with disability (YLDs) and disability-adjusted life years (DALYs) attributable to VAD by using the comparative risk assessment (CRA). VAD defined as low serum retinol concentrations (plasma retinol concentration $<0.70$ umole/L) among children aged less than five. The VAD outcomes consisted of mortality due to diarrhea, measles, malaria, neglected infectious diseases, morbidity due to malaria (children $<5$ years), low birth weight and other perinatal conditions. Uncertainty in the estimates is presented as 95\% uncertainty interval (UI).
\end{abstract}

Results: In 1990, there were 371 (95\% UI: 166,665) DALYs due to VAD per 100,000 under five-year-old Iranian children in both sexes. The DALYs rate had a downward trend throughout the following years and reached to 76 (95\% UI: 33-139) in 2010.The DALYs in children aged under 5 years was 378 (95\% UI: 153-747) years for boys and 363 (95\% Ul: 148-692) years for girls in 1990 which fell to 79 (95\% UI: 32-149) and 73 (95\% UI: 29-138) in boys and girls in 2010, respectively. The rates of YLDs attributable to VAD changed in both sexes from 87(95\% UI: 34-162) in 1990 to 46 (95\% UI: 17-69) in 2010. The highest rate of YLDs attributed to VAD was observed in children aged 1-4. On the other hand, the YLLs were mostly in the 0-1-year-oldchildren in all years except 2010.

Conclusion: It was found that DALYs attributable to VAD in 1990, followed by a considerable reduction rate after a period of two decades, in 2010. Additional studies on the burden of diseases particularly at sub-national level with more accurate data are recommended.

Keywords: Global burden of disease (GBD), Vitamin a deficiency, Disability-adjusted life years, Years lived with disability, Iran

\footnotetext{
* Correspondence: mqorbani1379@yahoo.com; Kelishadi@med.mui.ac.ir

${ }^{\dagger}$ Equal contributors

${ }^{2}$ Non-Communicable Diseases Research Center, Alborz University of Medical

Sciences, Baghestan Boulevard, Karaj 31485/56, Iran

${ }^{1}$ Child Growth and Development Research Center, Research Institute for

Primordial Prevention of Non-communicable Disease, Isfahan University of

Medical Sciences, Hezarjerib Ave, Isfahan, Iran

Full list of author information is available at the end of the article
} 


\section{Background}

Vitamin A is an essential micronutrient for growth, cell differentiation and proliferation, reproduction, eyesight, improved immune system, maintenance and protection of membrane integrity [1].Vitamin A and its active metabolite form, namely retinoic acidare essential for the development and function of different tissues such as the immune system [1].

Poor nutritional status, inadequate intake of vitamin A and infections such as diarrhea and measles are the most common causes leading to vitamin A deficiency (VAD) [2]. VAD is characterized using a serum or plasma retinol concentration of $<0.7 \mu \mathrm{mol} / \mathrm{L}$ as cut-off for $\operatorname{VAD}[1,2]$.

VAD is recognized as a serious public health problem in developing countries [3-5]. A large number of young children and pregnant women especially inlow-income and non-industrialized communities are more susceptible toVAD. It results in night blindness, xerophthalmia, infection, iron deficiency anemia, and increased mortalityrate [2].According to the World Health Report (2011), the global prevalence of VAD in 0-4- year- old children was close to $21 \%$, and the frequency of nightblindness was estimated to be $5 \%$ among pregnant women with the greatest prevalence in Asian and African countries [6-8].It is also estimated that approximately 190 million preschool children and19 million pregnant women are affected by VAD, worldwide [6]. VAD is a major cause of mortality in children under-five. Any improvement in vitamin A status might promote resistance to its health consequences and reduced mortality rate up to $23 \%$ [9].

Furthermore, VAD mightlead to the burden of diseases (BOD) as increasing the risk of susceptibility to infection, birth defects, blindness, cognitive disorders and premature mortality rates [2, 5, 10-12]. Previous global risk factor assessment revealed that 0.8 million (1.4\%) of deaths worldwide are due toVAD [13], andVAD was responsible for $1.8 \%$ of the global burden of diseases (GBD) measured in disability-adjusted life years (DALYs) $[7,14] . G B D$ is a study conducted by the Institute for Health Metrics and Evaluation (IHME) that calculated the GBD in 2010 [15].

Little information is available regarding vitamin A status among Iranian individuals [12] and there is no report of measured BOD related to VAD in Iran. This study aims to report the BOD attributable to VAD in Iranian population aged less than 5 years by using data of the GBD study from 1990 to 2010 [15].Furthermore, this study aims to compare the results with the similar findings and discuss about the limitations of the GBD project for estimating burden of VAD.

\section{Methods}

The GBD 2010 study calculated the proportion of death, years of life lost (YLLs), years lived with disability
(YLDs), and DALYs attributable to VAD between 1990 and 2010. The GBD study 2010 has calculated the proportion of death and DALYs attributable to VAD between 1990 and 2010. The details of data, data quality, and statistical models for GBD Study 2010 estimation are described previously [16-22]. The GBD 2010 study has categorized this nutrient deficiency as a risk factor in the cluster "childhood and maternal under nutrition" [23]. VAD was defined as low serum retinol concentrations $(<0.70 \mu \mathrm{mol} / \mathrm{L})$ among children under- 5 years of age. The outcomes resulting from VAD were considered as mortality due to diarrhea, measles, malaria, miscellaneous infectious causes of disease, morbidity due to malaria (children $<5$ yr) as well as low birth weight and other prenatal conditions.

The burden was estimated for all ages and in both sexes. However, in this study, the measures for under-five-yearold age group are reported becausethe burden of VAD was not noticeable in the other age groups. Details about estimating disease burden attributable to each risk factor have been explained elsewhere [23].After selecting riskoutcome pairs, distribution of exposure to each risk factor was estimated according to published and unpublished data sources. For vitamin A, key sources were comprehensive review of data from multiple sourcesincluding the World Health Organization (WHO) and Micronutrient Initiative summary reports, journal articles, published and unpublished survey reports.

In the last step, attributable deaths or DALYs to VAD were calculated by comparing the present distribution of exposure with the theoretical-minimum-risk counterfactual exposure distribution for each age group, sex, and year (1990-2010). For VAD, theoretical-minimum-risk exposure distribution was considered as $100 \%$ of the population being without VAD.

For each risk factor and disease pair, population attributablefraction (PAF) was calculated in each age and sex group. Uncertainty in the relative risks, exposure estimates, theoretical minimum risk distributions and uncertainty inthe background outcome rates have been propagated into the final estimates. Uncertainty in the estimates is presented as 95\% uncertainty interval (UI).

\section{Results}

The attributable burden of VAD among under-5-year-old age group during 1990-2010 is presented in Table 1 . There were 371 (95\% UI: 166-665) DALYs due to VAD per 100,000 Iranian children in both sexes. The DALYs rate had a downward trend throughout the following years and reached to 76 (95\% UI: 33-139) in 2010. The burden of DALYs in children aged under 5 years was 378 (153-747) years for boys and 363 (95\% UI: 148-692) years for girls in 1990 which fell to 79 (95\% UI: 32-149) and 73 (95\% UI: 29-138) respectively in boys and girls in 2010. Fig. 1 shows age-standardized DALYs rate (per 100,000 population) 
Table 1 Disability-adjusted life-years attributable rate (per 100000 population) to vitamin A deficiency by age, sex and year in Iran

\begin{tabular}{|c|c|c|c|c|c|}
\hline \multirow[b]{2}{*}{ Both sexes } & \multicolumn{5}{|l|}{ DALY [95\% UI] } \\
\hline & 1990 & 1995 & 2000 & 2005 & 2010 \\
\hline 0-1 year & $374[111,878]$ & $183[58,419]$ & $94[29,201]$ & $63[18,139]$ & $41[14,93]$ \\
\hline 1-4 year & $377[170,682]$ & $203[94,353]$ & $133[56,232]$ & $98[39,179]$ & $86[36,160]$ \\
\hline Under 5 year & $371[166,665]$ & $196[90,351]$ & $124[52,217]$ & $90[35,163]$ & $76[33,139]$ \\
\hline Age-standardized & $33[15,59]$ & $17[8,31]$ & $11[5,19]$ & $8[3,14]$ & $7[3,12]$ \\
\hline \multicolumn{6}{|l|}{ Boy } \\
\hline 0-1 year & $423[107,1060]$ & $204[54,537]$ & $102[28,262]$ & $66[16,168]$ & $44[12,119]$ \\
\hline 1-4 year & $375[152,758]$ & $205[87,397]$ & $135[53,263]$ & $101[37,194]$ & $89[36,168]$ \\
\hline Under 5 year & $378[153,747]$ & $202[83,370]$ & $128[50,242]$ & $93[34,176]$ & $79[32,149]$ \\
\hline Age-standardized & $33[14,66]$ & $27[11,49]$ & $11[4,21]$ & $8[3,16]$ & $7[3,13]$ \\
\hline \multicolumn{6}{|l|}{ Girl } \\
\hline 0-1 year & $324[72,865]$ & $162[37,461]$ & $86[21,244]$ & $59[13,158]$ & $38[10,110]$ \\
\hline 1-4 year & $378[155,712]$ & $200[85,359]$ & $130[54,234]$ & $95[37,181]$ & $83[33,158]$ \\
\hline Under 5 year & $363[148,692]$ & $191[82,341]$ & $120[49,216]$ & $86[33,161]$ & $73[29,138]$ \\
\hline Age-standardized & $32[13,61]$ & $17[7,30]$ & $11[4,19]$ & $8[3,14]$ & $6[3,12]$ \\
\hline
\end{tabular}

DALY Disability-adjusted life-years; UI Uncertainty interval

attributable to VAD by sex and year. The age-standardized DALYs rate had a downward trend throughout the following years in boys and girls and reached to 7 [95\% UI: 3, 13] and 6 (95\% UI: 3, 12) in 2010 in boys and girls respectively.

According to the GBD data, VAD is a risk factor for nutritional deficiencies and infectious diseases including diarrhea, lower respiratory infections, meningitis, and other common infectious diseases. However, the majority of DALYs attributable to this risk factor were from infectious diseases and nutritional deficiencies had a negligible role (data are not shown in table).

Tables 2 and 3 show the changes in YLDs and YLLs in children less than 5 years in Iran between 1990 and 2010.The rates of YLDs attributable to VAD and in both sexes changed from 87(95\% UI: 34-162) in 1990 to 46 (95\% UI: 17-69) in 2010.VADcaused the most disability burden (YLD) in the 1-4 year age group compared to children aged less than 1 year. On the other hand, burden of death affected mostly the $0-1$ - year age group in all years except for 2010 (Table 3).

The ranking of VAD as a risk factor in children less than 5 years between $1990-2010$ are shown in Table 4 . The ranking dropped from the eighth leading risk factor in 1990 to the 9th in 2010 in the $0-1$ year group, and from 6 th to 7 th in the 1-4 year age group.

The disease burden attributable to VAD decreased from $0.15 \%$ (95\% UI: $0.07-0.78$ ) of total DALYs in 1990 to $0.02 \%$ (95\% UI: $0.01-0.04)$ in 2010.

\section{Discussion}

The current study represents the first attempt to measure the disease burden attributable to VAD during 1990 - 2010 in Iran by using the data of the GBD study 2010 measured in DALYs. According to these findings, higher

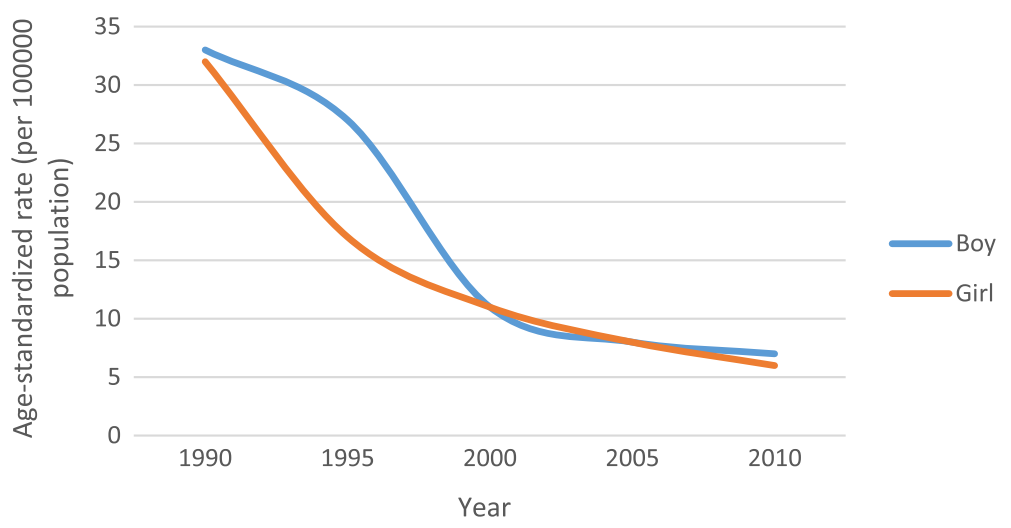

Fig. 1 Age-standardized DALYs rate (per 100000 population) to vitamin A deficiency by sex and year in Iran 
Table 2 Years lived with disability attributable rate (per 100000 population) to vitamin A deficiency by age, sex and year in Iran

\begin{tabular}{|c|c|c|c|c|c|}
\hline \multirow[b]{2}{*}{ Both sexes } & \multicolumn{5}{|l|}{ YLD [95\% UI] } \\
\hline & 1990 & 1995 & 2000 & 2005 & 2010 \\
\hline 0-1 year & $18[6,43]$ & $16[5,37]$ & $15[5,34]$ & $12[4,30]$ & $11[3,25]$ \\
\hline 1-4 year & $104[40,193]$ & $81[32,151]$ & $73[28,141]$ & $59[21,116]$ & $55[21,107]$ \\
\hline Under 5 year & $87[34,162]$ & $69[27,129]$ & $61[24,119]$ & $50[18,97]$ & $46[17,89]$ \\
\hline Age-standardized & $8[3,14]$ & $6[2,11]$ & $5[2,10]$ & $4[2,9]$ & $4[2,8]$ \\
\hline \multicolumn{6}{|l|}{ Boys } \\
\hline 0-1 year & $20[5,52]$ & $18[5,46]$ & $16[4,40]$ & $14[3,36]$ & $12[3,31]$ \\
\hline 1-4 year & $101[37,197]$ & $80[30,156]$ & $72[27,1437]$ & $59[20,122]$ & $55[20,112]$ \\
\hline Under 5 year & $85[31,164]$ & $68[25,132]$ & $61[22,121]$ & $50[17,101]$ & $46[17,93]$ \\
\hline Age-standardized & $7[3,14]$ & $6[2,11]$ & $5[2,10]$ & $4[1,9]$ & $4[1,8]$ \\
\hline \multicolumn{6}{|l|}{ Girls } \\
\hline 0-1 year & $16[4,43]$ & $14[3,37]$ & $13[3,34]$ & $11[3,29]$ & $10[2,28]$ \\
\hline 1-4 year & $106[38,206]$ & $83[30,159]$ & $73[27,140]$ & $59[20,118]$ & $54[19,114]$ \\
\hline Under 5 year & $88[32,171]$ & $70[25,132]$ & $62[23,118]$ & $49[17,98]$ & $45[16,93]$ \\
\hline Age-standardized & $8[3,15]$ & $6[2,11]$ & $5[2,10]$ & $4[1,9]$ & $4[1,8]$ \\
\hline
\end{tabular}

YLD Years lived with disability; UI Uncertainty interval

DALYs related to VAD was observed in the year 1990, followed by a considerable reduction rate after a period of two decades in 2010. The burden of VAD among Iranian children under 5 was estimated to be 371 and 76 DALYs per 100,000 populations in 1990 and 2010, respectively.

VAD is a major public health issue among preschool children living in developing countries and contributes to higher rates of infants and/or child mortality and disease burden compared to developed ones. The highest VAD prevalence has also been found in Africa, Mali, Ethiopia, Nigeria and
Egypt. Higher incidence of VAD is almost occurred in young children and pregnant women of low income and nonindustrialized countries [3,11, 24-27]. Previous reports have demonstrated that $33.8 \%$ of $0-4$ year old South-African children are VAD, and was responsible for $28 \%$ of all deaths resulted from diarrheal disease, 23\% from measles and 21\% from malaria among them in the age group of $0-4$ years. Improved vitamin A status could prevent 1.3-2.5 million of almost 8 million late infancy and pre-school aged deaths occurring each year in developing countries [7].

Table 3 Years of life lost attributable rate (per 100000 population) to vitamin A deficiency by age, sex and year in Iran

\begin{tabular}{|c|c|c|c|c|c|}
\hline \multirow[b]{2}{*}{ Both sexes } & \multicolumn{5}{|l|}{ YLL [95\% UI] } \\
\hline & 1990 & 1995 & 2000 & 2005 & 2010 \\
\hline 0-1year & $356[106,839]$ & $167[52,391]$ & $80[24,173]$ & $50[14,115]$ & $31[9,74]$ \\
\hline 1-4 year & $273[113,537]$ & $121[51,229]$ & $60[26,112]$ & $38[14,75]$ & $31[12,63]$ \\
\hline Under 5 year & $284[116,545]$ & $127[52,239]$ & $63[26,114]$ & $40[15,75]$ & $31[12,58]$ \\
\hline Age-standardized & $25[10,48]$ & $11[5,21]$ & $6[2,10]$ & $4[1,7]$ & $3[1,5]$ \\
\hline \multicolumn{6}{|l|}{ Boys } \\
\hline 0-1 year & $403[100,1016]$ & $186[48,501]$ & $86[23,231]$ & $53[11,139]$ & $32[8,94]$ \\
\hline 1-4 year & $274[98,573]$ & $124[47,268]$ & $64[23,123]$ & $42[14,91]$ & $34[11,72]$ \\
\hline Under 5 year & $293[108,622]$ & $133[52,268]$ & $66[24,127]$ & $43[15,91]$ & $33[12,68]$ \\
\hline Age-standardized & $26[10,55]$ & $12[5,24]$ & $6[2,11]$ & $4[1,8]$ & $3[1,6]$ \\
\hline \multicolumn{6}{|l|}{ Girls } \\
\hline 0-1 year & $308[66,831]$ & $148[33,425]$ & $73[17,217]$ & $48[10,136]$ & $29[6,86]$ \\
\hline 1-4 year & $272[103,540]$ & $118[47,230]$ & $57[22,113]$ & $35[12,75]$ & $28[10,60]$ \\
\hline Under 5 year & $275[104,561]$ & $121[48,238]$ & $59[23,119]$ & $37[13,76]$ & $28[10,59]$ \\
\hline Age-standardized & $45[17,92]$ & $11[4,21]$ & $5[2,11]$ & $3[1,7]$ & $2[1,5]$ \\
\hline
\end{tabular}

YLL Years of life lost; UI Uncertainty interval 
Table 4 Vitamin A deficiency mean rank [95\% UI] for both sexes in 1990 and 2010

\begin{tabular}{lll}
\hline DALY & 1990 mean rank (95\% UI) & 2010 mean rank(95\% UI) \\
\hline $0-1$ year & $8.8(7-10)$ & $9.7(7-11)$ \\
$1-4$ year & $6.2(3-9)$ & $7.3(4-10)$ \\
Under 5 years & $8.6(7-11)$ & $8.7(7-11)$ \\
Age standardized & $18.9(17-21)$ & $23.5(20-25)$ \\
\hline
\end{tabular}

DALY Disability-adjusted life-years; UI Uncertainty interval

During the past two decades, an outstanding improvement in health and sanitation combined with greater availability of health service facilities as well as improvement in the health knowledge of the population contributed in the control of preventable communicable diseases in Iran. However, a shift in the disease burden toward non-communicable chronic diseases (NCDs) occurred [28].Similar patterns of increasing trend in the prevalence of NCDs have also been emerged in other parts of the world [29-31].Likewise, the decreasing trend in the GBD related to VAD during the two recent decades was similar to the global reports as well as Middle-Eastern countries such as Iraq and Turkey. Declining the VAD prevalence might be due to widespread vitamin A supplementation with measles immunization among at risk population [32]. It seems that unfavorable lifestyle changes along with industrialization and urbanization increased the degree of exposure to NCDs risk factors as a major health concern. The worldwide rising epidemic of obesityrelated diseases reflects the significant alterations in society and behavioral patterns of community undergoing the nutritional and epidemiological transition over recent decades [33, 34].

In the current study, higher burden of VAD was observed among infants aged 0-1 year during 1990s. VAD in infancy is an indicator of inadequate vitamin A stores during pregnancy. As was found by most studies from developing countries, VAD pregnant mothers are more likely to have infants with insufficient vitamin A stores [35, 36].It seems that the deficiency in vitamin A status could remain even in the period of lactation [37].However, because of its vitamin A content, human milk is suggested to have a protective role against VAD [38].Previous reports have revealed that breastfed infants were more likely to have sufficient vitamin A levels and subsequently reduced frequency of infections $[5,39]$.

Over the past two decades, economic growth, urbanization, and the profound changes in social levels and the economic situation of the families have led to the improvement in vitamin A status of children [5].Additionally, higher levels of parental education and nutrition knowledge might be another reason associated with greater attention to healthy eating patterns, including vitamin A rich products [40].These factors might interfere with the results of the present study.
Another reason for higher disease burden of VAD during 1990s could be the establishment and availability of health care centers as well as health care facilities across the country. Over the past two decades, the number of active Health Houses and health centers have increased considerably proportional to the population size [41].

It is important to highlight that VAD is not a direct contributor to death by itself. The main determinant of higher mortality rates among children of developing countries would be the widespread prevalence of infections as diarrhea, respiratory disease, and measles [5, 42]. VAD might exacerbate the incidence, duration, and severity of infections through its immunomodulatory effects $[43,44]$.Promoting intervention-treatment programs to reduce the incidence of infectious diseases and improve child survival could help to explain the decrease in the VAD burdenin Iran and across the world.

Despite the equally available centers offering health care, utilization of health services in some provinces like Sistan and Baluchestan, it is estimated to be low compared to the rest of the country. It seems that factors such as people's attitude might play a role in this regard [45].Furthermore, lack of sufficient nutrition knowledge, high cost, and seasonal variations in vitamin A containing foods could be other barriers to modify overall diet quality in low-income households [5, 46, 47].

In this regard, it is worth mentioning that VAD had large variations within different rural areas and provinces in Iran. Therefore, providing an estimation of aggregate data on VAD mortality for all provinces of the country could conflict the results [42] but the GBD data are more accurate at global and national levels. In addition, GBD estimations aremore model-driven than data-driven for adopting appropriate policies to promote the health of the regions of a country by the authorities of health section. Therefore, sub-national studies with more data are necessary to estimate the burden of diseases more accurately to provide evidence for health policy makers. In this regard, recently, National and Sub-national Burden of Disease (NASBOD) study is conducted in Iran to calculate the burden of diseases, injuries and risk factors at national and sub-national levels from 1990 to 2013 [48, 49].Estimation of prevalence and burden of nutritional diseases and risk factors at sub-national level is a sub- project of NASBOD study [50].The above-mentioned study is a valuable 
one that benefits all published and unpublished data in the country and two statistical methods [51].

Unlike the aforementioned limitations, exploring and describing the burden of diseases attributable to VAD could potentially provide useful information on the importance of the problem. For instance, from 1 in 7 to 1 in 3 deaths might be prevented through improvement of nutritional adequacy of children aged 6 months up to preschool age in the developing world [35].Additionally, health system development, public health successes are areas where the country would need urgent action.

\section{Conclusion}

We found a considerable declining trend in the BODattributable to VAD among Iranian pre-school children in a period of 20 years. Additional studies on the burden of diseases including visual impairment and skin problems due to VAD are recommended.

\section{Abbreviations}

BOD: Burden of disease; CRA: Comparative risk assessment; DALYs: Disabilityadjusted life years; UI: Uncertainty interval; VAD: Vitamin A deficiency; YLDs: Years lived with disability; YLLs: Years of life lost

\section{Acknowledgements}

We thank Professor Christopher J.L. Murray, the head of Institute for Health Metric and Evaluation (IHME) for the permission to use the results of GBD for this paper. We also would like to thank the Ministry of Health and Medical Education of Islamic Republic of Iran, Setad-e-Ejraie Farmane Imam and all staffs and researchers of the NCDRC for their supports.

\section{Funding}

Ministry of Health and Medical Education of Islamic Republic of Iran.

\section{Availability of data and materials}

Please contact author for data requests.

\section{Authors' contributions}

$M B, M Q$ and $S N$, design, data analysis, and interpretation, SN, AAJ and FS, design, FS, MM and AK, design, AAA, HA and OS interpretation, interpretation, RK and MQ design and revision. All authors read and approved the final manuscript.

\section{Ethics approval and consent to participate}

Not applicable.

\section{Consent for publication}

Not applicable.

\section{Competing interests}

The authors declare that they have no competing interests.

\section{Publisher's Note}

Springer Nature remains neutral with regard to jurisdictional claims in published maps and institutional affiliations.

\section{Author details}

${ }^{1}$ Child Growth and Development Research Center, Research Institute for Primordial Prevention of Non-communicable Disease, Isfahan University of Medical Sciences, Hezarjerib Ave, Isfahan, Iran. ${ }^{2}$ Non-Communicable Diseases Research Center, Alborz University of Medical Sciences, Baghestan Boulevard, Karaj 31485/56, Iran. ${ }^{3}$ Non-Communicable Diseases Research Center, Endocrinology and Metabolism Population Sciences Institute, Tehran University of Medical Sciences, Tehran, Iran. ${ }^{4}$ Endocrinology and Metabolism Research Center, Endocrinology and Metabolism Research Institute, Tehran
University of Medical Sciences, Tehran, Iran. ${ }^{5}$ Department of Nutrition, Science and Research Branch, Islamic Azad University, Tehran, Iran. 'Elderly Health Research Center, Endocrinology and Metabolism Population Sciences Institute, Tehran University of Medical Sciences, Tehran, Iran. ${ }^{7}$ Health Management and Economics Research Center and Department of Health Education and Promotion, Iran University of Medical Sciences, Tehran, Iran. ${ }^{8}$ Department of Applied Linguistics, Tarbiat Modares University, Tehran, Iran. ${ }^{9}$ Department of Medical Emergencies, Qom University of Medical Sciences, Qom, Iran.

Received: 25 December 2016 Accepted: 24 July 2017

Published online: 09 August 2017

\section{References}

1. Beijer MR, Kraal G, den Haan JM. Vitamin A and dendritic cell differentiation. Immunology. 2014;142:39-45.

2. Allen L, de Benois B, Dary O, Hurrell R. Guidelines on food fortification with icronutrients. Geneva, World Health Organization and Food and Agricultural Organization of the United Nations, 2006.Available from: http://www.who. int/nutrition/publications/guide_food_fortification_micronutrients.pdf

3. de Queiroz D, Paiva Ade A, Pedraza DF, Cunha MA, Esteves GH, de Luna JG, et al. Vitamin a deficiency and associated factors in children in urban areas. Revista de saudepublica. 2013;47:248-56.

4. Danneskiold-Samsoe N, Fisker AB, Jorgensen MJ, Ravn H, Andersen A, Balde ID, et al. Determinants of vitamin a deficiency in children between 6 months and 2 years of age in Guinea-Bissau. BMC Public Health. 2013;13:172.

5. Sherwin JC, Reacher MH, Dean WH, Ngondi J. Epidemiology of vitamin a deficiency and xerophthalmia in at-risk populations. Trans R Soc Trop Med Hyg. 2012;106:205-14

6. West KP Jr. Extent of vitamin a deficiency among preschool children and women of reproductive age. J Nutr. 2002;132:2857S-66S.

7. Nojilana B, Norman R, Bradshaw D, van Stuijvenberg ME, Dhansay MA. Labadorios $D$, et al estimating the burden of disease attributable to vitamin a deficiency in South Africa in 2000. S Afr Med J. 2007;97:748-53.

8. WHO. Vitamin A deficiency. Geneva, World Health Organization:(http://www who.int/nutrition/topics/vad/ en/index.html, accessed 2 July 2011).

9. United Nations Children's Fund (UNICEF). Vitamin A supplementation: a decade of progress. New York: UNICEF; 2007. Available from: http://www. unicef.org/publications/files/Vitamin_A_Supplementation.pdf.

10. Agarwal R, Virmani D, Jaipal M, Gupta S, Toteja GS. Vitamin a status of low and normal birth weight infants at birth and in early infancy. Indian Pediatr. 2013;50:951-3.

11. Agrawal VK. Agrawal P, Dharmendra. Prevalence and determinants of xerophthalmia in rural children of Uttarpradesh, India. Nepal J Ophthalmol. 2013:5:226-9.

12. Mirmiran P, Golzarand M, Serra-Majem L, Azizi F. Iron, iodine and vitamin a in the middle east; a systematic review of deficiency and food fortification. Iran J Public Health. 2012:41:8-19.

13. The World Health Report 2002: reducing risks, promoting healthy life. Geneva, World Health Organization, 2002. Available from: http://whqlibdoc. who.int/publications/2002/9241562072.pdf

14. Sommer A, Davidson FR. Assessment and control of vitamin a deficiency: the Annecy accords. J Nutr. 2002;132:2845S-50S.

15. Mokdad $\mathrm{AH}$. Adolescent health in the Eastern Mediterranean Region: findings from the global burden of disease 2015 study. Int J Public Health. 2017. doi:10.1007/s00038-017-1003-4.

16. Murray CJ, Ezzati M, Flaxman AD, Lim S, Lozano R, Michaud C, et al. GBD 2010: design, definitions, and metrics. Lancet. 2012;380:2063-6.

17. Wang H, Dwyer-Lindgren L, Lofgren KT, Rajaratnam JK, Marcus JR, LevinRector A, et al. Age-specific and sex-specific mortality in 187 countries, 1970-2010: a systematic analysis for the global burden of disease study 2010. Lancet. 2012;380:2071-94.

18. Lozano R, Naghavi M, Foreman K, Lim S, Shibuya K, Aboyans V, et al. Global and regional mortality from 235 causes of death for 20 age groups in 1990 and 2010: a systematic analysis for the global burden of disease study 2010. Lancet. 2012;380:2095-128.

19. Salomon JA, Vos T, Hogan DR, Gagnon M, Naghavi M, Mokdad A, et al. Common values in assessing health outcomes from disease and injury: disability weights measurement study for the global burden of disease study 2010. Lancet. 2012;380:2129-43. 
20. Salomon JA, Wang H, Freeman MK, Vos T, Flaxman AD, Lopez AD, et al. Healthy life expectancy for 187 countries, 1990-2010: a systematic analysis for the global burden disease study 2010. Lancet. 2012;380:2144-62.

21. Vos T, Flaxman AD, Naghavi M, Lozano R, Michaud C, Ezzati M. Years lived with disability (YLDs) for 1160 sequelae of 289 diseases and injuries 19902010: a systematic analysis for the global burden of disease study 2010. Lancet. 2012;380:2163-96.

22. Murray CJ, Vos T, Lozano R, Naghavi M, Flaxman AD, Michaud C, et al. Disability-adjusted life years (DALYs) for 291 diseases and injuries in 21 regions, 1990-2010: a systematic analysis for the global burden of disease study 2010. Lancet. 2012;380:2197-223.

23. Lim SS, Vos T, Flaxman AD, Danaei G, Shibuya K, Adair-Rohani H, et al. A comparative risk assessment of burden of disease and injury attributable to 67 risk factors and risk factor clusters in 21 regions, 1990-2010: a systematic analysis for the global burden of disease study 2010. Lancet. 2012 5:380:2224-60.

24. Gebreselassie SG, Gase FE, Deressa MU. Prevalence and correlates of prenatal vitamin a deficiency in rural Sidama. Southern Ethiopia J Health Popul Nutr. 2013;31:185-94.

25. Vuralli D, Tumer L, Hasanoglu A, Biberoglu G, Pasaoglu H. Vitamin a status and factors associated in healthy school-age children. Clin Nutr. 2014;33:509-12.

26. Olang B, Naghavi M, Bastani D, Strandvik B, Yngve A. Optimal vitamin a and suboptimal vitamin D status are common in Iranian infants. Acta Paediatr. 2011;100:439-44

27. Rostami N, Farsar AR, Shiva N. Prevalence of sub-clinical vitamin a deficiency in 2-5-year-old children in Tehran. East Mediterr Health J. 2007:13:273-9.

28. Khajehkazemi R, Sadeghirad B, Karamouzian M, Fallah MS, Mehrolhassani $\mathrm{MH}$, Dehnavieh $\mathrm{R}$, et al. The projection of burden of disease in Islamic Republic of Iran to 2025. PLoS One. 2013;8:e76881.

29. Alwan A, Maclean DR. A review of non-communicable disease in low- and middle-income countries. Int health. 2009;1:3-9.

30. Mathers CD, Loncar D. Projections of global mortality and burden of disease from 2002 to 2030. PLoS Med. 2006;3:e442.

31. Abegunde DO, Mathers CD, Adam T, Ortegon M, Strong K. The burden and costs of chronic diseases in low-income and middle-income countries. Lancet. 2007;370:1929-38.

32. Institute for HealthMetrics and Evaluation. Available from: URL: http://www. healthdata.org/. Accessed 1 Apr 2013.

33. lannotti RJ, Wang J. Patterns of physical activity, sedentary behavior, and diet in U.S. adolescents. J Adolesc Health. 2013;53:280-6.

34. Ortega Anta RM, Lopez-Solaber AM, Perez-Farinos N. Associated factors of obesity in Spanish representative samples. Nutricion Hosp. 2013;28(Suppl 5):56-62.

35. Lee V, Ahmed F, Wada S, Ahmed T, Ahmed AS, Parvin Banu C, et al. Extent of vitamin a deficiency among rural pregnant women in Bangladesh. Public Health Nutr. 2008:11:1326-31.

36. El-Khashab EK, Hamdy AM, Maher KM, Fouad MA, Abbas GZ. Effect of maternal vitamin a deficiency during pregnancy on neonatal kidney size. J Perinat Med. 2013;41:199-203.

37. Samba C, Tchibindat F, Gourmel B, Houze P, Malvy D. Prevalence of vitamin a deficiency in pregnant and lactating women in the republic of Congo. J Health Popul Nutr. 2013;31:28-36.

38. Souza G, Saunders C, Dolinsky M, Queiroz J, Campos A, Ramalho A. Vitamin a concentration in mature human milk. J Pediatr. 2012;88:496-502.

39. Mele L, West KP Jr. Kusdiono, Pandji a, Nendrawati H, Tilden RL, et al. nutritional and household risk factors for xerophthalmia in Aceh, Indonesia: a case-control study. The Aceh study group. Am J Clin Nutr. 1991:53:1460-5.

40. Schemann JF, Malvy D, Zefack G, Traore L, Sacko D, Sanoussi B, et al. Mapping xerophthalmia in Mali: results of a national survey on regional distribution and related risk factors. J Am Coll Nutr. 2007;26:630-8.

41. Hosseinpoor AR, Mohammad K, Majdzadeh R, Naghavi M, Abolhassani F Sousa A, et al. Socioeconomic inequality in infant mortality in Iran and across its provinces. Bull World Health Organ. 2005;83:837-44.

42. Humphrey JH, West KP Jr, Sommer A. Vitamin a deficiency and attributable mortality among under-5-year-olds. Bull World Health Organ. 1992:70:225-32.

43. Mullin GE. Vitamin A and immunity. Nutr Clin Pract 2011;26:495-496.

44. Cassani B, Villablanca EJ, De Calisto J, Wang S, Mora JR. Vitamin a and immune regulation: role of retinoic acid in gut-associated dendritic cell education, immune protection and tolerance. Mol Asp Med. 2012;33:63-76.

45. Population and health in the Islamic Republic of Iran. Iran Demographic and Health Survey Report. Tehran, Ministry of Health and Medical Education, 2000.
46. van den Briel T, Cheung E, Zewari J, Khan R. Fortifying food in the field to boost nutrition: case studies from Afghanistan, Angola, and Zambia. Food Nutr Bull. 2007;28:353-64.

47. Dizaji MB, Taghdisi MH, Solhi M, Hoseini SM, Shafieyan Z, Qorbani M, et al. Effects of educational intervention based on PRECEDE model on self-care behaviors and control in patients with type 2 diabetes in 2012. J Diabetes Metab Disord. 2014;16:13-72

48. Farzadfar F, Delavari A, Malekzadeh R, Mesdaghinia A, Jamshidi HR, Sayyari A, et al. NASBOD 2013: design, definitions, and metrics. Arch Iran Med. 2014;17:7-15.

49. Ghasemian A, Ataie-Jafari A, Khatibzadeh S, Mirarefin M, Jafari L, Nejatinamini S, et al. National and sub-national burden of chronic diseases attributable to lifestyle risk factors in Iran 1990 - 2013; study protocol. Arch Iran Med. 2014;17:146-58.

50. Kasaeian A, Eshraghian MR, RahimiForoushani A, NiakanKalhori SR, Mohammad K, Farzadfar F. Bayesian autoregressive multilevel modeling of burden of diseases, injuries and risk factors in Iran 1990 - 2013. Arch Iran Med. 2014;17:22-7.

51. Parsaeian M, Farzadfar F, Zeraati H, Mahmoudi M, Rahimighazikalayeh G, Navidi I, et al. Application of spatio-temporal model to estimate burden of diseases, injuries and risk factors in Iran 1990 - 2013. Arch Iran Med. 2014;17:28-33.

\section{Submit your next manuscript to BioMed Central and we will help you at every step:}

- We accept pre-submission inquiries

- Our selector tool helps you to find the most relevant journal

- We provide round the clock customer support

- Convenient online submission

- Thorough peer review

- Inclusion in PubMed and all major indexing services

- Maximum visibility for your research

Submit your manuscript at www.biomedcentral.com/submit 